\title{
A national census of medicines use: a 24-hour snapshot of Australians aged 50 years and older
}

\section{Tessa K Morgan \\ BSC, BA, MPH \\ Research Officer \\ Margaret Williamson BPharm, MPH, GradDipEpi, Manager, Research and Development $^{\top}$ \\ Marie Pirotta MB BS, MMed, PhD Senior Lecturer \\ Kay Stewart BPharm(Hons), PhD, Associate Professor in Pharmacy \\ Stephen P Myers PhD, BMed, ND, Director, Health and Wellbeing Research Cluster \\ Joanne Barnes BPharm(Hons), PhD, MRPharmS Associate Professor in Herbal Medicines \\ 1 National Prescribing Service, Sydney, NSW. \\ 2 Department of General Practice University of Melbourne Melbourne, VIC. \\ 3 Centre for Medicine Use and Safety, Monash University, Melbourne, VIC \\ 4 School of Health and Human Sciences, Southern Cross University, Lismore, NSW. \\ 5 School of Pharmacy, University of Auckland, Auckland, NZ. \\ tmorgan@nps.org.au}

MJA 2012; 196: 50-53 doi: 10.5694/mjall.10698
T he use of medicines for the treatment of disease is a common health-related action by Australians. Medicines are not only used to treat diagnosed medical conditions but, increasingly, to manage risk factors. ${ }^{1}$ Individuals' ${ }^{\prime}$ patterns of medicines use are not well understood, including the combined use of prescription, over-the-counter (OTC) and complementary medicines. Smaller surveys of specific populations' use of medicines have been conducted, ${ }^{2,3}$ but the most recent Australia-wide survey was the 1995 National Health Survey. ${ }^{4}$ A majority of published Australian research on the use of medicines is based on the analysis of dispensing data from the Australian Pharmaceutical Benefits Scheme and the Repatriation Pharmaceutical Benefits Scheme; however, these data sources do not include OTC, complementary and unsubsidised prescription medicines. ${ }^{5}$

Use of and access to medicines is changing. An ageing population is contributing to the national increase in medicine consumption and cost. ${ }^{6}$ The popularity of complementary medicines has led to increased access to these products through conventional sources of non-prescription medicines, such as pharmacies and supermarkets, as well as through complementary medicine practitioners. ${ }^{7,8}$ Our study, a national census of medicines use, aimed to address current knowledge gaps by exploring current use of prescription, OTC and

\section{Definitions}

Medicines: Everything taken or used to keep you healthy, or to treat a symptom or an illness. Includes prescription and non-prescription (over-the-counter) medicines, complementary, herbal and alternative medicines, vitamin supplements, homeopathic remedies, eye drops, creams, lotions, patches, suppositories and pessaries. Complementary medicines: Based on the Therapeutic Goods Administration definition. Includes vitamins, minerals, nutritional supplements and herbal, aromatherapy and homeopathic products. Conventional medicines: Prescription and over-the-counter medicines not classified as complementary medicines. Regular medicines: Taken daily or at regular intervals over time. Occasional medicines: Taken only when needed. Polypharmacy: Five or more medicines used in 24 hours.

Objective: To explore the current use of conventional and complementary medicines in Australians aged $\geqslant 50$ years.

Design, setting and participants: Cross-sectional postal survey sent to a random sample of 4500 Australians aged $\geqslant 50$ years between June 2009 and February 2010.

Main outcome measures: Prevalence of medicines use, reasons for medicines use and sources of medicines.

Results: Response rate was $37.3 \%$. Medicines use was very common; $87.1 \%$ of participants took one or more medicines and $43.3 \%$ took five or more in the previous 24 hours. Complementary medicines were used by $46.3 \%$ of participants, $87.4 \%$ of whom used both conventional and complementary medicines. The most commonly used medicines were antihypertensive agents (43.2\% of participants), natural marine and animal products including fish oil and glucosamine (32.4\%) and lipid-lowering agents (30.4\%). Doctors recommended $79.3 \%$ of all medicines and $93.0 \%$ of conventional medicines. Pharmacists commonly recommended occasional medicines (ie, as needed), while friends, family and media most often influenced use of complementary medicines.

Conclusions: The use of multiple medicines is common and higher than reported in the 1995 National Health Survey. Today, much medicines use is to prevent future disease by influencing risk factors. High levels of polypharmacy highlight the need to support the safe and effective use of medicines in the community. Although doctors recommend or prescribe most medicines, selfdirected medication use is common. This highlights the need for consumer access to accurate information and strategies to improve health literacy about medicines.

complementary medicines, and the patterns and predictors of their use, by Australians aged 50 years and older.

\section{Methods}

Our descriptive study used a crosssectional survey sent to a random sample of 4500 Australians aged 50 years and older. We sent out four mailings between June 2009 and February 2010 (to allow for potential seasonal variation). The survey was developed from pilot work conducted by the University of Melbourne, which compared a medicines diary with at-home pharmacist interviews and found that self-recording of medicines used was valid. ${ }^{9}$

\section{Questionnaire content}

A two-section questionnaire collected information on the use of all medicines. An inclusive definition of medi- cines was provided for participants (Box 1). The questionnaire was supplied only in English.

The first section included a diary to record medicines used in the previous 24 hours and all other medicines used in the previous month. The following information was requested for each medicine: reason for use, whether use was regular or occasional, who prescribed or recommended it, source, cost, and date first started.

The second section included multiple-choice and open-response questions about health status, lifestyle factors, chronic health conditions, how medicines information was obtained, the influence of cost on medicines use, problems with medicines, and basic demographic characteristics.

\section{Sampling and data collection}

The Australian Electoral Commission provided a random sample, stratified 


2 Participant characteristics -
National Census of Medicines Use
(June 2009 - February 2010)

ABS $=$ Australian Bureau of Statistics

* Unweighted for age and sex. †ABS 2009

estimate for the Australian population.

by state or territory, of 4500 Australians aged 50 years and older. An invitation postcard was sent to potential participants explaining the study aims, with an opportunity to opt out. Participants were encouraged to take part even if they did not use medicines. Two weeks later, the study questionnaire was sent with an introductory letter. To maximise the response rate, a reminder postcard was sent 3 weeks later, and a reminder letter and second questionnaire were sent to non-responders after another 2 weeks.

Participants were ineligible if they were absent during the study period or unable to complete the questionnaire due to inability to read or write English, illness, disability or death, or if questionnaires were returned because of a change of address.

The study was approved by the University of Melbourne Human Research Ethics Committee.

\section{Coding and analysis}

Medicines were grouped by class, adapted from the classification system used by MIMS (Monthly index of medical specialties; http://www.mims. com.au). Up to three active ingredients were coded for each product. The components of multivitamin and multimineral complexes were not coded individually. The reasons for each medicine's use were classified by the researchers to reflect participants' descriptions. Data from the second section of the questionnaire were scanned into a database and merged with data from the first. Descriptive analysis was undertaken using SPSS, version 18.0 (SPSS Inc, Chicago, Ill, USA). Bivariate analyses were conducted using the $\chi^{2}$ test. Poststratification weights were applied using Australian population estimates for age and sex. ${ }^{10}$ Data that have not been weighted for age and sex are referred to as unweighted data.

\section{Results}

A total of 1608 questionnaires were returned. Of the 4500 potential participants, 191 were ineligible; therefore the response rate was $37.3 \%{ }^{11}$ Data are reported only for the use of medicines in the previous 24 hours.

\section{Participants' characteristics}

Study participants had similar sex and age distributions to those of the Australian population, ${ }^{11}$ with the exception of people aged $50-54$ years, who were significantly underrepresented in unweighted data (Box 2).

\section{Prevalence of medicines use}

Most participants had used at least one conventional or complementary medicine in the previous 24 hours $(87.1 \%)$, with a mean of 4.6 medicines per participant (range, 0-31). Women were more likely to be medicines users than were men $(90.3 \% \mathrm{v} 83.9 \%$; $P<0.001)$. Most participants $(84.2 \%)$ used one or more medicines regularly; $28.2 \%$ also used an occasional medicine in the same 24-hour period.

In total, $43.3 \%$ of participants reported use of five or more medicines of any type in the previous 24 hours, and $10.7 \%$ reported using 10 or more medicines. Almost a third (30.5\%) used five or more conventional medicines, and 5.1\% reported using five or more complementary medicines. (The number of medicines used, by age and sex, is shown in Box 3.) Polypharmacy was significantly associated with increasing age $(32.2 \%, 49.4 \%$ and $66.0 \%$ for ages $50-64,65-74$ and $\geqslant 75$ years, respectively; $P<0.001)$ and being female (50.2\% v 35.3\%; $P<0.001)$. Participants who selfreported "fair" or "poor" health status were significantly more likely to use more medicines than were those reporting "excellent" or "good" health $(72.4 \%$ v $36.4 \% ; P<0.001)$.

\section{Medicines used}

A total of 1400 participants reported 7337 medicines used in the previous 24 hours, of which $89.2 \%$ were taken regularly and $10.8 \%$ were taken occasionally. Antihypertensive agents, natural marine and animal products and lipid-lowering agents were the most common classes of medicines used (Box 4).

With the exception of antidepressants, use of the most common conventional medicines increased with age. Antidepressant use was lowest among 65-74 year olds. Women were more likely than men to use antidepressants $(12.4 \%$ v $6.2 \% ; P<0.001)$ and agents affecting calcium and bone metabolism (21.4\% v 4.4\%; $P<0.001)$.

The most commonly used active ingredients taken in either single- or

\section{Number of medicines used in the previous 24 hours, by age group and sex - National Census of Medicines Use (June 2009 - February 2010)}

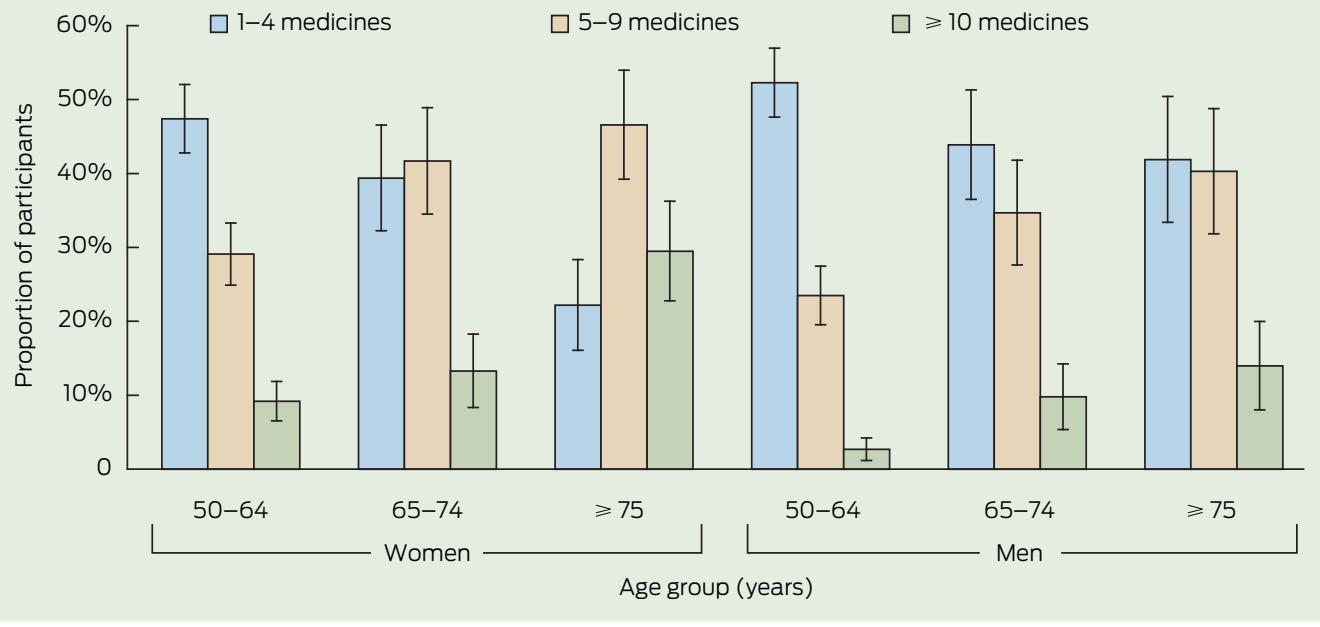


4 Most commonly used medicine classes in the previous 24 hours, with selected active ingredients, by age group - National Census of Medicines Use (June 2009 - February 2010)

\begin{tabular}{|c|c|c|c|c|}
\hline Medicine class and selected active ingredients & $\begin{array}{l}\text { All age } \\
\text { groups }\end{array}$ & $\begin{array}{c}50-64 \\
\text { years }\end{array}$ & $\begin{array}{l}65-74 \\
\text { years }\end{array}$ & $\begin{array}{l}\geqslant 75 \\
\text { years }\end{array}$ \\
\hline Antihypertensive agents* & $43.2 \%$ & $29.9 \%$ & $56.0 \%$ & $64.5 \%{ }^{\dagger}$ \\
\hline Hydrochlorothiazide & $9.3 \%$ & $6.1 \%$ & $12.7 \%$ & $14.3 \%{ }^{\dagger}$ \\
\hline Irbesartan & $9.4 \%$ & $6.3 \%$ & $11.2 \%$ & $15.6 \%{ }^{\dagger}$ \\
\hline Natural marine and animal products ${ }^{\ddagger}$ & $32.4 \%$ & $34.0 \%$ & $33.9 \%$ & $27.1 \%$ \\
\hline Omega-3 marine triglycerides (fish oil) & $25.2 \%$ & $26.7 \%$ & $27.2 \%$ & $18.9 \%$ \\
\hline Glucosamine ${ }^{\text {q }}$ & $16.8 \%$ & $18.2 \%$ & $17.2 \%$ & $13.4 \%$ \\
\hline Lipid-lowering agents & $30.4 \%$ & $21.5 \%$ & $41.0 \%$ & $42.7 \% \%^{\dagger}$ \\
\hline Atorvastatin & $14.5 \%$ & $11.1 \%$ & $17.4 \%$ & $21.8 \%{ }^{\dagger}$ \\
\hline Simvastatin & $7.4 \%$ & $4.3 \%$ & $9.9 \%$ & $11.7 \%{ }^{\dagger}$ \\
\hline Anticoagulants, antithrombotics** & $25.3 \%$ & $12.7 \%$ & $32.9 \%$ & $51.3 \%{ }^{\dagger}$ \\
\hline Agents for gastric acidity, reflux and ulcers & $21.0 \%$ & $14.2 \%$ & $26.5 \%$ & $33.0 \%{ }^{\dagger}$ \\
\hline Simple analgesics and antipyretics** & $18.6 \%$ & $15.6 \%$ & $16.8 \%$ & $27.9 \%{ }^{\dagger}$ \\
\hline Multivitamins and minerals (including B-group multivitamins) ${ }^{\ddagger}$ & $14.6 \%$ & $15.3 \%$ & $14.9 \%$ & $12.1 \%$ \\
\hline Agents affecting calcium and bone metabolism ${ }^{\ddagger}$ & $13.2 \%$ & $9.4 \%$ & $11.9 \%$ & $25.4 \%{ }^{\dagger}$ \\
\hline Calcium & $11.6 \%$ & $10.3 \%$ & $10.8 \%$ & $16.2 \%{ }^{\dagger}$ \\
\hline Cholecalciferol (vitamin D) & $10.8 \%$ & $9.2 \%$ & $9.8 \%$ & $16.5 \%{ }^{\dagger}$ \\
\hline$\beta$-adrenergic blocking agents & $12.2 \%$ & $6.6 \%$ & $17.0 \%$ & $22.3 \%{ }^{\dagger}$ \\
\hline Non-steroidal anti-inflammatory agents & $10.7 \%$ & $9.8 \%$ & $10.9 \%$ & $13.2 \%$ \\
\hline Antidepressant agents & $9.4 \%$ & $9.4 \%$ & $7.8 \%$ & $11.1 \%$ \\
\hline
\end{tabular}

multicomponent products were omega-3 marine triglycerides (such as fish oils), paracetamol, aspirin and glucosamine. Age differences existed for the use of several of these ingredients (Box 4).

More comprehensive tables of results for medicine components and medicine classes used are available at http://www.nps.org.au/research/medicinecensus/tables.

\section{Complementary and conventional medicines}

Complementary medicines were used by $46.3 \%$ of participants, representing just over half $(53.2 \%)$ of all medicines users, $87.4 \%$ of whom used both conventional and complementary medicines. The mean number of complementary medicines used was 1.2 (range, 0-19). Women used more complementary medicines in the previous 24 hours than did men $(1.5 \mathrm{v}$ $0.8 ; P<0.001)$. The use of only conventional medicines increased with age, while the use of only complementary medicines decreased (Box 5).

\section{Reasons for medicines use}

More than 150 different reasons for medicines use were reported, including $31.1 \%$ for cardiovascular conditions, $16.6 \%$ for musculoskeletal conditions (including joint and bone health) and $8.4 \%$ for general health and wellbeing (including "energy", "inner health" and "weight loss"). The most frequent specific reasons for use were hypertension $(13.2 \%$ of medicines), arthritis (8.5\%), general health $(8.0 \%)$ and lipid lowering (7.2\%).

Occasional medicines were most often used for pain relief, including headaches $(13.0 \%)$, arthritis $(7.6 \%)$, musculoskeletal pain (including muscle cramps) $(7.4 \%)$, and general pain $(6.2 \%)$
Complementary medicines were commonly used for general health $(29.3 \%)$, arthritis $(20.2 \%)$, bone health and disease prevention (6.7\%) and joint health and disease prevention $(4.7 \%)$.

\section{Access to medicines and sources of recommendations}

Medicines were purchased from pharmacies $(84.8 \%)$, supermarkets (7.0\%), health food shops (5.4\%) and the internet $(0.7 \%)$. Pharmacies were the main source for conventional $(94.7 \%)$ and complementary medicines $(53.2 \%)$. Supermarkets, health food shops and the internet were also sources of complementary medicines $(17.6 \%, 20.2 \%$ and $2.7 \%$ of complementary medicines, respectively).

Doctors recommended $79.3 \%$ of all medicines and $93.0 \%$ of conventional medicines. Compared with regular medicines, more occasional medicines were recommended by pharmacists $(10.5 \%$ v $2.9 \% ; P<0.001)$. Complementary medicines were more likely to be recommended by the media or by friends and family than were conventional medicines (media, 18.6\% v 1.1\%; $P<0.001$; family and friends, $17.6 \% \mathrm{v} 1.5 \%$; $P<0.001)$.

\section{Discussion}

For many older Australians, managing complex medicine regimens is a necessary and challenging part of life.

Our results indicate a high prevalence of medicines use among this sample: $87 \%$ had used at least one medicine of any type in the previous

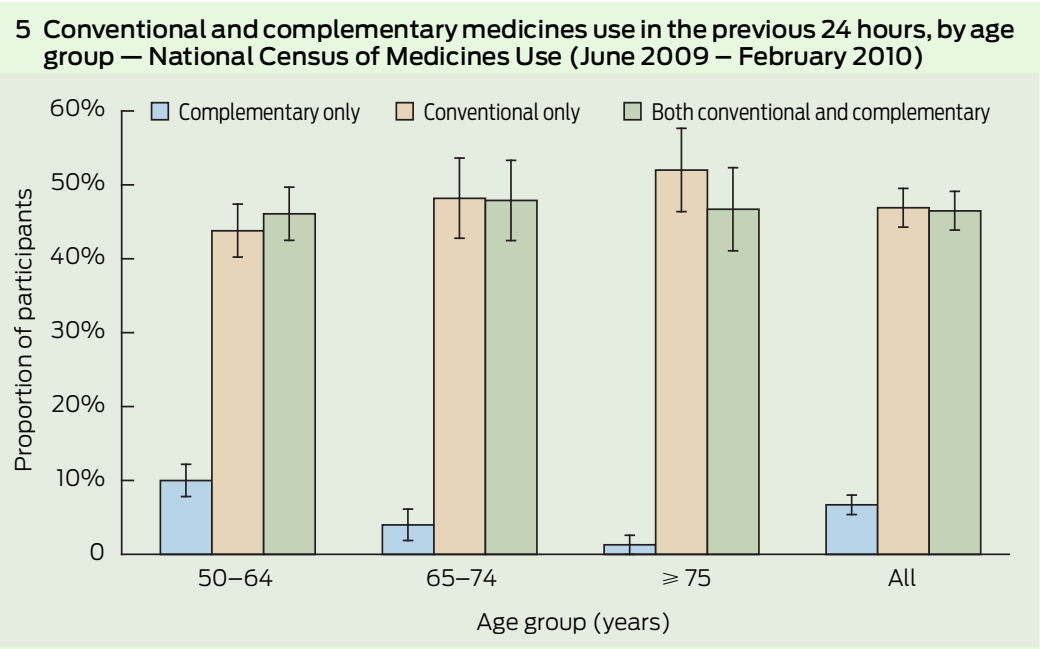


24 hours and, of these, 97\% had used one or more regular medicines. Furthermore, polypharmacy was common $(42.9 \%)$, particularly among participants aged $\geqslant 75$ years $(66.0 \%)$.

Although medicines can play a pivotal role in the quality of life of older people, polypharmacy can contribute to non-adherence and increase the risk of adverse drug reactions. ${ }^{12-14}$ Many consumers and health professionals may be unaware of the risk of potential interactions with complementary mediciness. ${ }^{7,15}$ Although the 1995 National Health Survey provided limited data on medicines use and involved a different recall period from our study (2 weeks compared with 24 hours), a simple comparison indicates that patterns of medicines use have changed over the past 15 years. In this period, the proportion of medicines users taking six or more conventional medicines increased by $13.9 \%$ to $39.8 \%$, varying by age group and greatest among people aged $\geqslant 85$ years $(16.2 \%$ to $56.0 \%)$. There was also a substantial increase in the use of some medication classes. In 1995, $4.8 \%$ of participants (aged $\geqslant 45$ years) used a lipid-lowering agent, compared with $30.4 \%$ in the present study, and the use of antidepressants increased from $3.7 \%$ to $9.4 \% .{ }^{4}$

Some medicines use is self-directed without professional advice: one in eight medicines was purchased from a supermarket, health food store or the internet and a similar proportion was first recommended by family, friends or the media. This highlights the importance of facilitating both consumer access to accurate medicines information and health literacy.

Medicines are commonly used to modify health risks and improve wellbeing, rather than to treat symptoms or disease. Hypertension, lipid lowering and general health represented three of the top four reasons for medicines use, with most complementary medicines use relating to general health and wellbeing. This signals a change in behaviour since the 1995 National Health Survey and, possibly, a change in how consumers see the place and purpose of medicines in their lives.
Our response rate may have introduced bias, as use of medicines may differ between responders and nonresponders. The proportion of people taking medicines was similar to that found in recent United States studies. ${ }^{16,17}$ The response rate of $37 \%$ is reasonable compared with other postal surveys using Australian electoral enrollees. ${ }^{18}$ The sample had similar age and sex characteristics to the Australian population, although people aged 50-54 years were underrepresented. This may have been due to higher family or work commitments, or less interest due to lower medication use. To address differences, data were weighted to Australian Bureau of Statistics population estimates for age and sex. The use of a national random sample, a comprehensive and valid questionnaire to measure all medicines use, evidence-based bestpractice methods for improving the response rate in postal surveys ${ }^{19}$ and the collection of medicines data in different seasons all strengthen the results of this study.

For Australians aged 50 years and older, the prevalence of medicines use is high, and use of multiple medicines is common. This highlights the need to support the safe and effective use of medicines in the community and the need for further research into appropriateness of medicines use.

Increasingly, medicines are being used to prevent illness. This trend may have a long-term positive impact on public health and will likely have cost implications for the Pharmaceutical Benefits Scheme. This also highlights the need for the ongoing promotion of healthy lifestyle changes.

Acknowledgements: This research was funded by the Australian Department of Health and Ageing through the National Prescribing Service and the University of Melbourne. Marie Pirotta is funded by a Primary Health Care Research Evaluation and Development fellowship. We also acknowledge the contribution of Rebecca Coleman and Liane Johnson for their advice during project development, Vinay Prasad for her support in distribution, and Jonathon Dartnell and Lynn Weekes for their thoughtfu contribution to editing this article.

Competing interests: No relevant disclosures.

Received 6 Jun 2011, accepted 29 Aug 2011.

1 Australian Institute of Health and Welfare Australia's health 2010. Canberra: AlHW, 2010. (AIHW Cat. No. AUS 122; Australia's Health Series No. 12.)

2 Byles JE, Heinze R, Nair BK, et al. Medication use among older Australian veterans and war widows. Int Med J 2003; 33: 388-392.
3 Hancock L, Walsh R, Henry DA, et al. Drug use in Australia: a community prevalence study. Med J Aust 1992; 156: 759-764.

4 Australian Bureau of Statistics. National Health Survey: use of medications, Australia, 1995. Canberra: ABS, 1999. (ABS Cat. No. 4377.0.) http:// www.abs.gov.au/ausstats/abs@.nsf/productsby topic/BF60D2B59D518692CA2568 A9001393D1?OpenDocument (accessed Dec 2011).

5 Department of Health and Ageing. Australian statistics on medicines 2006. Canberra: Commonwealth of Australia, 2008.

6 Department of Health and Ageing. The impact of PBS reform. Report to Parliament on the National Health Amendment (Pharmaceutical Benefits Scheme) Act 2007. Canberra: Commonwealth of Australia, 2010

7 Williamson M, Tudball J, Toms M, et al. Information use and needs of complementary medicines users. Sydney: National Prescribing Service, 2008. http:// www.nps.org.au/research_and_evaluation/ research/current research/complementary medicines/cms_users_research/complementary medicines_consumer_research (accessed Mar 2011)

8 MacLennan AH, Myers SP, Taylor AW. The continuing use of complementary and alternative medicine in South Australia: costs and beliefs in 2004. Med J Aust 2006; 184: 27-31.

9 Pirotta M, Lau P, Stewart K, et al. Australians' use of medicines - comparison of data gathered by 7-day and 1-day diary and by pharmacist interview. Proceedings of the General Practice and Primary Health Care Research Conference; 2006 Jul 5-7; Perth, Australia. http://www.phcris.org.au/ conference/browse.php?id=2343\&spindex= $3 \&$ catid $=158 \&$ page $=1 \&$ subcat $=$ all \&search $=$ Pirotta (accessed Aug 2011).

10 Australian Bureau of Statistics. Australian demographic statistics, Jun 2009. Canberra: ABS 2009. (ABS Cat. No. 3101.0.) http://www.abs. gov.au/AUSSTATS/abs@.nsf/0/EB76EA379A44 E842CA2576F0001C70C9?opendocument (accessed Dec 2011).

11 Data Analysis Australia. Response rates. http:// www.daa.com.au/analytical-ideas/response-rates/ (accessed Feb 2011).

12 Easton K, Morgan T, Williamson M. Medication safety in the community: a review of the literature. Sydney: National Prescribing Service, 2009. http:// www.nps.org.au/research_and_evaluation/current research/medication_safety_community/ complementary_medicines_report (accessed Mar 2011)

13 Cohen I, Rogers P, Burke V, et al. Predictors of medication use, compliance and symptoms of hypotension in a community-based sample of elderly men and women. J Clin Pharm Ther 1998; 23: 423-432.

14 Johnson M, Griffiths R, Piper M, et al. Risk factors for an untoward medication event among elders in community-based nursing caseloads in Australia. Public Health Nurs 2005; 22: 36-44.

15 Pirotta M, Kotsirilos V, Brown J, et al. Complementary medicine in general practice: a national survey of GP attitudes and knowledge. Aust Fam Physician 2010; 39: 946-950.

16 Slone Epidemiology Center. Patterns of medication use in the United States 2006: a report from the Slone Survey. Boston: Boston University, 2006.

17 National Center for Health Statistics. Health, United States, 2010: with special feature on death and dying. Hyattsville, Md: NCHS, 2011

18 Breen CL, Shakeshaft AP, Doran CM, et al. Costeffectiveness of follow-up contact for a postal survey: a randomised controlled trial. Aust NZ J Public Health 2010; 34: 508-512.

19 Edwards PJ, Roberts IG, Clarke MJ, et al. Methods to increase response rates to postal questionnaires. Cochrane Database Syst Rev 2007; (2): MR000008. 